\title{
Complexity in Interpretation of Embryonic Epithelial-Mesenchymal Transition in Response to Transforming Growth Factor- $\beta$ Signaling
}

\author{
Shaheen Ahmed Ali Nawshad \\ Department of Oral Biology, College of Dentistry, University of Nebraska Medical Center, Lincoln, Nebr., USA
}

\section{Key Words}

Transforming growth factor- $\beta$ - Epithelial-mesenchymal transitions, embryonic

\begin{abstract}
Epithelial-mesenchymal transition (EMT) is a highly conserved and fundamental process that governs morphogenesis in development and may also contribute to cancer metastasis. Transforming growth factor (TGF- $\beta$ ) is a potent inducer of EMT in various developmental and tumor systems. The analysis of TGF- $\beta$ signal transduction pathways is now considered a critically important area of biology, since many defects occur in these pathways in embryonic development. The complexity of TGF- $\beta$ signal transduction networks is overwhelming due to the large numbers of interacting constituents, complicated feedforward, feedback and crosstalk circuitry mechanisms that they involve in addition to the cellular kinetics and enzymatics that contribute to cell signaling. As a result of this complexity, apparently simple but highly important questions remain unanswered, that is, how do epithelial cells respond to such TGF- $\beta$ signals? System biology and cellular kinetics play a crucial role in cellular function; omissions of such a critical contributor may lead to inaccurate understanding of embryonic EMT. In this review, we identify and explain why certain conditions need to be considered for a true representation of TGF- $\beta$ signaling in vivo to better understand the controlled, yet delicate mechanism of embryonic EMT.

Copyright $\odot 2007$ S. Karger AG, Basel
\end{abstract}

\section{Introduction}

Epithelial-mesenchymal transitions (EMT) are phenomena of great importance in embryonic development [Thiery, 2003b]. EMT regulates important processes during early development of all vertebrates and in the absence of EMT, development cannot proceed past the blastula stage [Thiery and Sleeman, 2006]. The generally accepted views on EMT suggest that it has an active role in tissue remodeling, organ development and wound healing, as well as cancer progression [Thiery, 2003b]. This review consolidates our interest in embryonic EMT from the previous broader focus on morphogenic changes in

\section{Abbreviations used in this paper}

\section{D 2-dimensional}

BMPs bone morphogenetic proteins

CDKs cyclin-dependent kinases

ECM extracellular matrix

EMT epithelial-mesenchymal transition

FGFR fibroblast growth factor receptor

HGF hepatocyte growth factor

IGF insulin-like growth factor

MAPK mitogen-activated protein kinase

PDGF platelet-derived growth factor

PI3K phosphatidylinositol 3-kinase

SBE Smad binding element

TGF- $\beta \quad$ transforming growth factor- $\beta$

$\begin{array}{ll}\text { KARGER } & \text { @ 2007 S. Karger AG, Basel } \\ \text { Fax }+41613061234 & 1422-6405 / 07 / 1853-0131 \$ 23.50 / 0 \\ \begin{array}{l}\text { E-Mail karger@karger.ch } \\ \text { www.karger.com }\end{array} & \begin{array}{l}\text { Accessible online at: } \\ \text { www.karger.com/cto }\end{array}\end{array}$

Dr. Ali Nawshad

Department of Oral Biology

College of Dentistry, University of Nebraska Medical Center

40th and Holdrege, Lincoln, NE 68583 (USA)

Tel. +1 402472 1378, Fax +1 402472 2551, E-Mail anawshad@unmc.edu 
response to transforming growth factor- $\beta$ (TGF- $\beta$ ) signaling. The least changed theme is an interest in the signal transduction biology surrounding EMT.

Achieving an understanding of what determines the dynamic responses of TGF- $\beta$ pathways will become increasingly important in developmental biology and, of course, important in studies of embryonic EMT. We became increasingly intrigued with the TGF- $\beta$ signaling and EMT, and the question of how epithelial cells respond to such signals remains somewhat unanswered. Moreover, defining the cell behavior during EMT in molecular terms is still ambiguous. Prof. Elizabeth Hay, who has done the most thorough analysis of EMT, proposed four functional criteria based on morphology and invasive motility, for defining a mesenchymal cell: it must have (1) front end-back end polarity, (2) elongate morphology, (3) filopodia, and (4) invasive motility. The four points in this definition of the mesenchymal cell were endorsed by a vote at the first Boden International Conference on EMT in Port Douglas, Australia, 2003. Attempts there to ascribe any molecular definition were inconclusive.

The regulation of cell adhesion is at the heart of epithelial architecture and remodeling during development [Birchmeier et al., 1996]. The most prominent feature of EMT is the complete loss of epithelial traits, such as Ecadherin, by the former epithelial cells and the acquisition of mesenchymal characteristics, such as vimentin, fibronectin, invasive motility, and so on [Takeichi, 1991, 1993]. What drives a group of epithelial cells to give up their phenotypical features and transform into a distinctly different cell type is still under intense investigation. There is a lot that we do not understand about EMT. The biggest weakness in our understanding is the connection between signaling and cell behavior. While there are several interesting approaches to this problem, we should be able to learn much from simply assembling a more complete picture of the localization and timing of signals within the cells during the process of cellular transformation in vivo.

The TGF- $\beta$ superfamily, which includes three different isoforms 1, 2, 3, as well as the bone morphogenetic proteins (BMPs) and activins, can exert multiple functions in cell/tissue specific manner. Depending upon the isoform, the TGF- $\beta$ superfamily can promote cell proliferation, differentiation, cell cycle arrest, apoptosis and transformation in a time- and system-dependent manner (fig. 1). The analysis of TGF- $\beta$ signal transduction pathways is now considered a critically important area of biology, where many defects occur in these pathways in embryonic development (as well as in tumor systems). How TGF- $\beta$ pathways function to handle such diverse respons- es within an organism and how these pathways function in new contexts in evolution remains mysterious. It has been proposed that the timing of signals, their coincidence, and/or the level of a signal may be responsible for the selective activation of TGF- $\beta$ pathways. The problems are much more complicated because the components of TGF- $\beta$ signaling pathways are not unique and many of the molecules that function downstream of the ligand-receptor interaction are linked by several shared components. Moreover, even though protein-protein interactions are often weak, the interactions of substrates with enzymes occurs with near perfect specificity [Roberts, $2002]$. All these criteria which effect TGF- $\beta$ signaling are often overlooked and contribute to the complexity in interpreting the TGF- $\beta$ signaling in developmental EMT.

We list here a few problems in determining cell behavior, motility, signal interpretation, and the broader developmental EMT, due to the complexity and nature of TGF- $\beta$ signaling towards a better understanding of how this consequential and integrated process transforms the epithelial cells.

(1) How do the TGF- $\beta$ signaling pathways process information? Various clues suggest that the downstream of the TGF- $\beta$ receptors lie Smad and non-Smad pathways. While the Smad pathways seem linear and better understood, the mechanisms through which non-Smad signaling pathways (particularly mitogen-activated protein kinases, MAPK) are activated and what these pathways contribute to the cellular response is poorly defined.

(2) There is a lot that we do not understand about TGF$\beta$ signaling during embryonic EMT. For example, does the TGF- $\beta$ signaling pathway play a direct role both in repression of epithelia markers and activation mesenchymal markers? If so, does this happen simultaneously or in a time-dependent fashion?

(3) What are the regulatory mechanisms that cause morphogenetic changes for convergent transformation of epithelial cells into mesenchymal cells?

(4) How do we characterize the transfer of information down the MAPK pathway theoretically and experimentally in reconstituting this pathway in an embryo. Can a quantitative and accurate model of the MAPK pathway be generated, and can it be used to distinguish activation by different transcription factors as well as EMT-related genes?

(5) As we look at the spatial disposition of TGF- $\beta$ signaling components, the question remains, can TGF- $\beta$ alone induce all features of EMT? Moreover, can all features of in vivo embryonic EMT be accurately reproduced using in vitro systems? 
What is particularly interesting from a cellular perspective is that even though there are limited numbers of easily accessible tissues with which to study TGF- $\beta$ signaling and multicellular behavior in a physiologically normal setting during embryonic EMT (such as primary embryonic epithelium during gastrulation, neurulation and neural crest formation, lung morphogenesis, ventral somite de-epithelialization to form the sclerotome, endocardial endothelium to form the endocardial cushions in the atrioventricular canal of the heart and medial edge epithelial cells during palate development), the comparison of such important phenomena is mostly done in systems which are far from a true representation of embryonic EMT (such as cancer cell lines). The scope of this review is not to address the concerns (mentioned above) but to understand the factors that may contribute to an inaccurate interpretation of the EMT in response by TGF- $\beta$ signaling. A detailed look at the characteristics and stages of EMT may facilitate a better grasp of the underlying problems which are often overlooked.

\section{Features of Embryonic EMT}

During the process of EMT in vertebrate development, there is an interpretation of secreted signals by complex intra- and extracellular circuits and changes in gene expression, resulting in coordinated cell movements and multicellular morphogenesis of complex embryonic structures. A detailed depiction of stages and features of embryonic EMT has been given by Shook and Keller [Shook and Keller, 2003]. According to them an embryonic epithelial cell programmed for EMT generally undergoes some or all of the following steps [modified from Shook and Keller, 2003] (fig. 2):

(1) Significant changes in gene expression and protein function that must all work in concert for a developmental EMT to occur correctly. This will direct the subsequent steps and may require cessation of cell division so that the cytoskeleton can be used to drive the cell shape changes and motility needed for EMT.

(2) Generally by an apical actin-myosin contractile mechanism, changes in cell-cell adhesion, loss of the coherent contact between neighbors that characterizes a particular epithelium, and the eventual loss of apical junctions, specifically the tight and adherens junctions, may contribute to epithelial cell shape change, which is essential to facilitate EMT.

(3) Acquiring mesenchymal phenotype and behavior process begins prior to migration by turning off epithe- lial characters or markers (E-cadherin/L-CAM, cytokeratin, laminin, and type IV collagen) and turning on mesenchymal characters or markers (vimentin intermediate filaments, fibronectin, and type I collagen). This requires a major reorganization of the cell, including completely dismantling the apical junctional 'scaffold' that is thought to regulate apical and basolateral discrimination by vesicular traffic [Rashbass and Skaer, 2000], and organization of the cytoskeleton. This, with the removal of the apical membrane, results in the loss of the cell's apicalbasal polarity.

(4) Migratory cells often alter or disrupt the basal lamina and move past or through a basal lamina, which may otherwise mechanically impede their ingression and therefore must be disrupted.

(5) Large areas of epithelium destined to EMT usually undergo patterning which allows both a necessary maintenance of physiological and mechanical continuity of the remaining epithelium, and the spatial regulation of morphogenesis.

(6) Generally through epithelial morphogenesis, movement of cells to the correct position of EMT is required, as in the chick or mouse primitive streak where large areas of epithelium are moved to a local site of ingression.

Additionally, the cytoskeleton must be remodeled, from what is believed to be a static, structural epithelial configuration to a dynamic, migratory configuration, a process that involves change from epithelial cytokeratins to mesenchymal vimentins, and probably substantial changes in regulation of actin polymerization, microtubule dynamics and myosin function to allow protrusive activity. Moreover, it is important that EMTs occur in the correct place, at the right time and in the right sequence, such that progenitor cells come to lie in the appropriate pattern [Thiery, 2003a].

All these features could aid and abet removing the cell from the epithelium; however, cells do not detach and move away from the epithelial layer under normal conditions [Thiery and Sleeman, 2006], which is probably why EMT is a widely distributed phenomenon in development but not in the adult. As stated above, there are numerous features required for the physiological/embryonic EMT (some are mentioned above, points 1-6). One might question whether TGF- $\beta$ alone is capable of contributing to all these steps during EMT. Given the multiple roles of TGF- $\beta$, it is not impossible for TGF- $\beta$ to contribute many if not all features and stages. It has been already established that EMT is an immensely important yet very complex mechanism, and this complexity is often com- 
Fig. 1. TGF- $\beta$ is a multipotent growth factor family: the TGF- $\beta$ superfamily can exert multiple functions in a cell/tissue-specific manner. Depending upon the isoforms (1, 2, 3, and the BMPs and activins), the TGF- $\beta$ superfamily can promote cell proliferation, differentiation, cell cycle arrest, apoptosis and/or transformation in a time- and system-dependent manner. However, whether all these roles are directly or indirectly related to the EMT or not still remains to be investigated.

Fig. 2. Can TGF- $\beta$ signaling complete all stages of EMT? (i) Typical epithelial cells have apical basal polarity, seats on basement membrane, are rich with epithelial markers such as tight junction proteins (e.g. ZO1), adherens junction proteins (e.g. E-cadherin) and desmosomes. (ii) Upon TGF- $\beta$ signaling these epithelial markers are repressed. Once these proteins are lost, epithelial cells get isolated from their adjacent cells. (iii) Individual epithelial cells begin to transform to mesenchymal cells, interact and degrade basement membrane proteins (basal lamina) while they rearrange their cytoskeletal proteins (e.g. $\alpha$ smooth muscle actin, microtubles and intermediate filaments) which help in acquiring front-end back-end polarity. (iv) TGF- $\beta$ signaling also activates the mesenchymal markers vimentin and fibronectin to become full-blown mesenchymal cells for migration through the ECM.
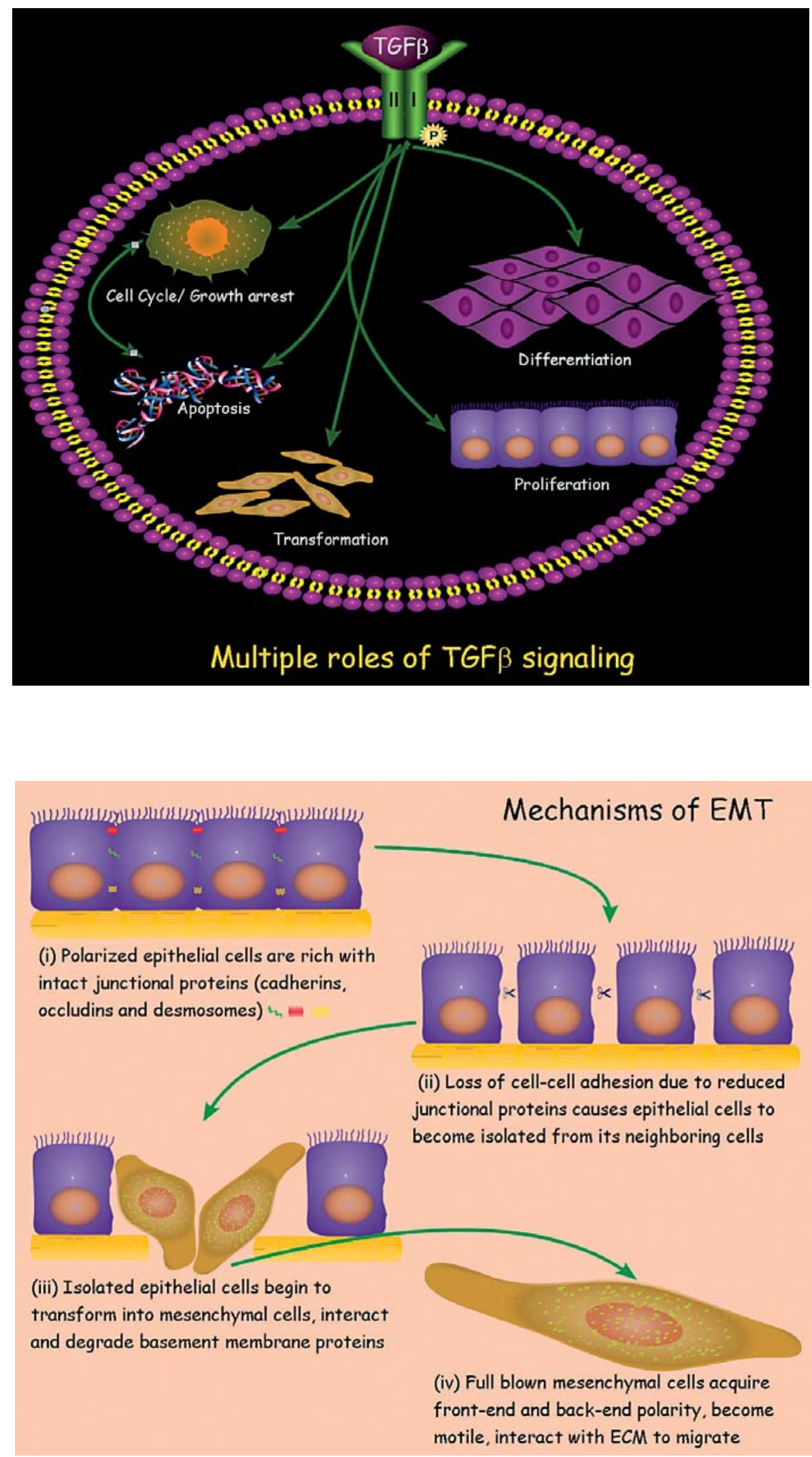
pounded by the methods used to define a complex phenomenon such as EMT, as well as the complicated multiple pathways of TGF- $\beta$. There are several impediments that contribute to an inaccurate interpretation of embryonic EMT; some are avoidable but many are not, and they are:

(1) The physiological and embryonic conditions in vivo cannot be accurately duplicated in vitro. They are mimicked as closely as possible in experimental conditions and therefore remain a challenge to all researchers.

(2) To demonstrate the mechanisms of TGF- $\beta$ signaling during EMT, most studies are done by exogenous treatment of TGF- $\beta$ in cell culture, and often using cancer cell lines with a compromised cellular component to begin with. Therefore experimental conditions used to study EMT are far from the actual in vivo embryonic conditions, and the results obtained could be flawed.

(3) TGF- $\beta$ can signal through numerous enzymes via multiple pathways to activate many transcription factors which regulate a number of genes to generate several cellular outcomes, such as proliferation, differentiation, cell cycle arrest and apoptosis (fig. 3, 4). The question is whether all these genes and transcription factors are necessary for EMT, and if not, how TGF- $\beta$ signaling does selectively activate what is required for EMT and repress that which is not. Moreover, many EMT-related genes (such as E-cadherin, vimentin and fibronectin) can be regulated via several pathways other than TGF- $\beta$. So the next question is: Do other growth factors simultaneously signal in parallel to TGF- $\beta$ to activate EMT-related genes?

(4) Lastly, embryonic EMT results in the formation of fully active, invasive mesenchymal cells, and we emphasize the importance of studying the physiologically relevant TGF- $\beta$ signal of transduction pathways that lead to the acquisition of invasive motility in vivo, rather than nonmotile actin bundle-rich cells in vitro. The nonmotile actin 'stress fibers' are an artifact of actin polymerization in 2-dimensional (2D) culture and are not a truly accurate reflection of in vivo motility.

\section{Factors Influencing Incorrect Interpreting of TGF- $\beta$ Signaling in Embryonic EMT}

\section{Morphological}

TGF- $\beta$ signal transduction pathways that modulate epithelial plasticity have been analyzed in culture using various epithelial cell lines. The term 'EMT' has been used in a rather loose fashion to encompass a much more diverse set of epithelial-plasticity phenotypes, thereby creating confusion in the field. Many of these experiments have been carried out in standard, 2D cultures. This impairs epithelial polarization, as some nutrients and growth factors cannot pass through the tight junctions of a fully polarized monolayer and so fail to reach their basolaterally located receptors that face the culture substratum [Grunert et al., 2003]. During such experimental conditions, epithelial markers (e.g. E-cadherin and integrin) are sometimes redistributed, but not lost, and mesenchymal markers such as vimentin are sometimes not induced [Grunert et al., 2003].

As briefly stated earlier, often cancer cell lines are used to define EMT in response to TGF- $\beta$ signaling on the basis of the presence of stress fibers. Under these conditions, cells became migratory and fibroblastoid in shape and lose epithelial polarity, with a concomitant redistribution/reduced expression of epithelial markers (E-cadherin). However, they failed to fully induce mesenchymal gene expression programs [Grunert et al., 2003]. The cytoskeletal end product stimulated by this signaling in cell lines is usually stress fibers [Aspenstrom et al., 2004]. Stress fibers have been shown to completely inhibit fibroblast migration in vitro [Herman et al., 1981].

In contrast to scattering, true EMT is completed only after 4-6 days of exposure to several signals, and occurs only in certain cell types, some of which require 3D culture conditions to rapidly and synchronously undergo EMT [Grunert et al., 2003]. As some cells that are capable of EMT undergo scattering after short-term factor treatment, one crucial parameter for inducing scattering or EMT might be acute versus chronic signal exposure. The full-blown mesenchymal cell has no E-cadherin and the only junctions it forms are transitory gap junctions when passing other mesenchymal cells [Hay, 2005]. The typical mesenchymal cell in vivo is polarized for cell locomotion, with a trailing pseudopodium and an active front end that produces filopodia which interact with extracellular matrix (ECM) in a 3D configuration [Hay, 2005]. This basic definition of the mesenchymal cell requires it to possess locomotive ability in or on ECM. A total artifact can be created if mesenchymal cells are removed from the body and cultured on flat (planer) substrates, such as coverslip without exogenous ECM. The cell flattens out and loses its elongated, polarized form. Most if not all of its myosin and actin molecules needed for cell locomotion polymerize inside so-called stress fibers and are missing from the cell cortex and endoplasm [Hay, 2005; Nawshad et al., 2005]. The healthy mesenchymal cell is a secretory cell and its products are mainly collagen and fibronectin, 
Fig. 3. TGF- $\beta$ signaling. Smad-dependent: TGF- $\beta$ ligand binds to receptors I and II at the cell surface. After phosphorylation of TGF $\beta R I$ with TGF $\beta$ RII kinase, the receptor forms a complex with Smad2 or Smad3. Smad2 (or Smad3) is phosphorylated and then complexes with Smad4 to enter the nucleus and activate EMT-related gene. Smad-independent: TGF- $\beta$ can also signal through the MAPK such as ERK and p38 to activate several transcription factors that induce target gene expression as well as via the PI3K and RhoA pathways, which have been shown to be key mediators of EMT. MAPK can also activate Jagged1, which in turn signals via NOTCH to activate bHLH-related transcription factors. At the end, these activated transcription factors (the ' $\mathrm{X}$ ' transcription factors) bind to appropriate binding sites of the EMT genes and either alone (-) or with (+) Smads bound at Smad binding elements (SBE) can regulate EMT-related genes. These activities can be regulated by corepressors and coactivators such as p300/CBP or Ski/ SnoN (green arrows are the flow of the signals and red arrows are the repressors).

Fig. 4. TGF- $\beta$ activated several transcription factors to modulate EMT: upon activation of the TGF- $\beta$ signaling via Smad or non-Smad pathways (MAPK, RhoA and PI3P), several transcription factors such as basic helix-loop-helix factors (bHLH) as well zinc finger factors can be activated. E-cadherin is commonly repressed by these transcription factors (as shown by round and oval structures bound onto the DNA in the nucleus) by promoting E-cadherin gene silencing, thus activating EMT. These transcription factors can be activated by several external stimulations other than TGF- $\beta$, such as Wnt, integrin, stress, BMPs and activins, interferons and number of growth factors [such as epidermal growth factors (EFG), HGF, PDGF and IGF]. It is quite intriguing.
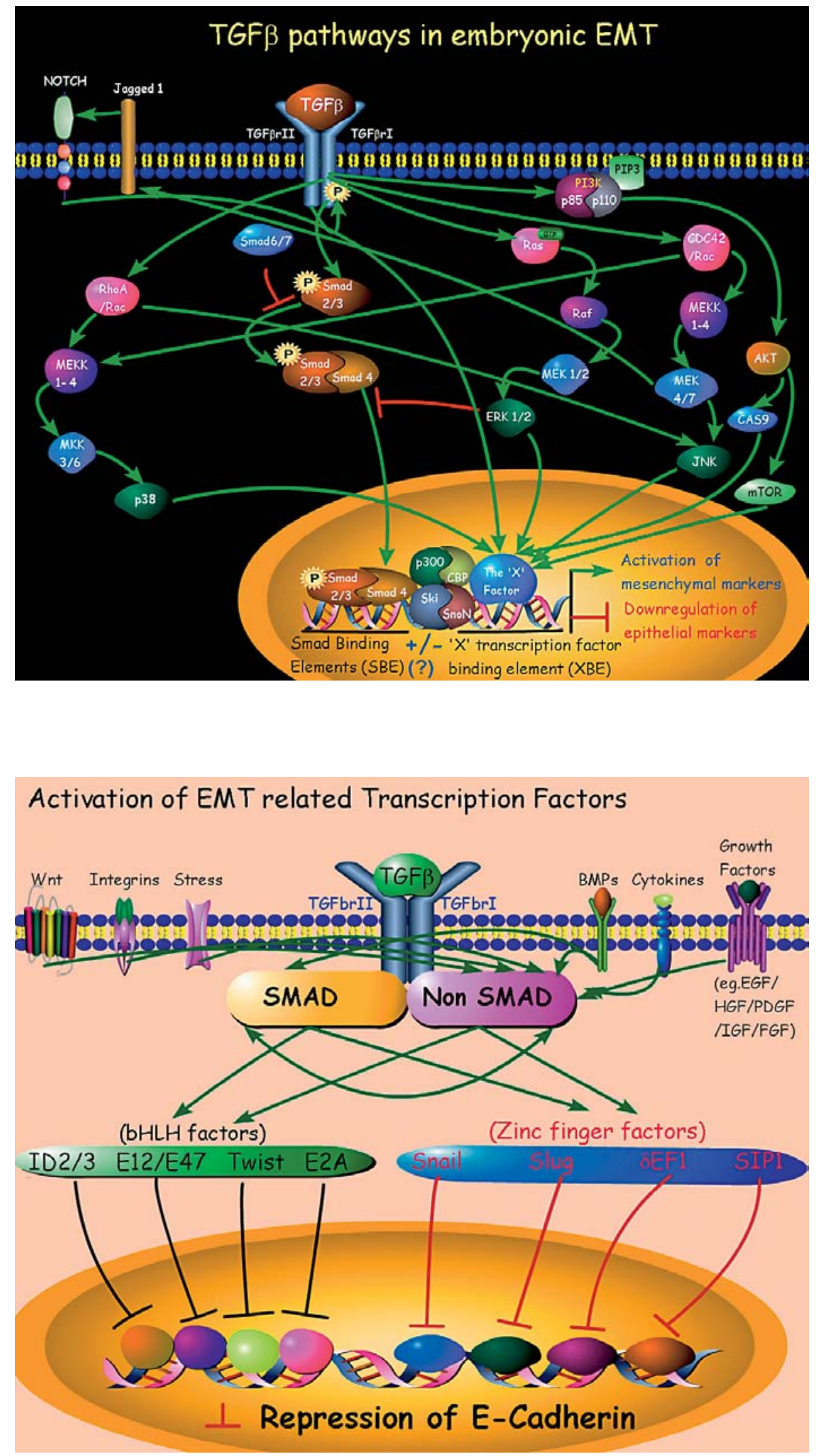
which are secreted via the Golgi complex at the front end behind the filopodia. For this reason, the term fibroblast (makes fibers) is often used to refer to the mesenchyme [Hay, 2005].

\section{Quantitative/Real Time}

The growing knowledge of how TGF- $\beta$ signaling proteins function and interact with each other has enabled us to draw maps of large networks, and has at the same time overwhelmed us with its enormous complexity. Complete understanding of signaling is therefore a difficult task, and it cannot be attained on the basis of interaction maps alone. A control analysis of a detailed kinetic model of TGF- $\beta$-induced MAPK signaling, which plays a pivotal role in the EMT, is needed.

For any signal transduction system, three key questions are:

(1) How fast does the signal arrive at its destination?

(2) How long does the signal last?

(3) How strong is the signal?

To provide answers to these questions, a model needs to be introduced with three key parameters: (1) the signaling time, which is the average time to activate kinases, (2) the signal duration, which is the average time during which kinases remain activated, and (3) the signal amplitude. There have been several efforts recently to model the behavior of TGF- $\beta$ signaling pathways. In many cases, limited quantitative information is available from experiments and the models are mostly heuristic and simplified. In other cases, various methods are used to get more complete information from direct measurements. The limitations of these kinds of approaches are generally not theoretical but experimental, the difficulty in assigning accurate values to kinetic and thermodynamic parameters, which are not generally accessible. The history of efforts to model TGF- $\beta$ pathways shows the difficulties we will face. There was an extensive body of kinetic information collected on enzymes, but when efforts were made to model pathways and predict fluxes and perturbations, it was quickly realized that the measurements were made under the wrong conditions. In particular, good enzymologists were always told to measure initial rates but in real systems the back reactions are equally important. Concepts such as rate-limiting reactions made no sense under realistic kinetic conditions obtained in vivo [Fell et al., 1997].

These three parameters may not account for the detailed kinetics of TGF- $\beta$ signaling systems, but they should be sufficient to describe most responses. Moreover, each of these parameters, mentioned earlier, may have a biological impact. For example, critical signal amplitude may be needed to evoke a biological effect. Signal amplification may not always be required, so long as the signal arrives at its final target (such as EMT transcription factor). Most likely, fast signaling is desirable in all signal transduction. However, signal duration may have to be short in some cases, for example, in a metabolic response, and longer in others, such as in a transcriptional response. For example, the signal amplitude is influenced more by kinases than by phosphatases. Signaling rate and duration, on the other hand, are mostly regulated by phosphatases [Asthagiri and Lauffenburger, 2000]. In the simplest TGF- $\beta$ pathway undergoing weak activation, the kinases have no role in determining signaling rate or duration. In more complicated systems, kinases can have a moderate effect, but still a smaller one than the phosphatases.

A recent numerical simulation supports these conclusions for the specific example of the MAPK pathway [Asthagiri and Lauffenburger, 2001]. Obviously, the amplitude of signal output is limited; its maximum is reached when the final target is fully phosphorylated. In contrast, signal duration can, at least in principle, be unlimited [Heinrich et al., 2002]. Thus, phosphatases, which largely determine signal duration, can have a significantly stronger effect than kinases on the biological outcome of a pathway. This critical role of the phosphatase is limited to normal TGF- $\beta$ signaling, in which the system returns to an inactive ground state. In contrast, when a pathway is permanently turned 'on', kinases can play a major role [Danuser, 2005]. Indeed, many known oncogenic mutations cause constitutive activation of a kinase.

Analysis of more complicated signaling pathways suggests that scaffolding proteins may serve several, not mutually exclusive functions. One possibility is that kinases become activated only when bound to a scaffolding protein. In this case, the kinases either are not utilized efficiently for the given pathway or are prevented from interacting with each other, depending on the relative concentrations of kinases and scaffolding protein; a similar conclusion was reached from a numerical simulation [Levchenko et al., 2000]. A second possibility is that scaffolding proteins might allow faster signaling in the pathway by preventing phosphatases from acting on the bound kinases. Finally, and likely most importantly, a scaffolding protein may allow a complex of consecutive kinases to be recruited to an activated receptor at the plasma membrane, leaving the unbound kinases inactive in bulk solution. A theoretical treatment of signal transduction via kinase cascades has been developed [Heinrich et al., 
2002] with particular attention to the role of scaffolding proteins. Often scaffolds are ignored as only playing a role in localization rather than in regulating signaling. Scaffolding proteins have a significant effect on the processing of information and on the dynamics of the outputs.

To understand the quantitative flow of information through the Smad-independent MAPK pathways, we need a system where the kinetics can be quantitatively measured and modeled. It is evident that specific phosphorylation events in components of the MAPK pathway, and in related components, need to be followed using a new method of quantitation employing mass spectroscopy [Stemmann et al., 2001]. In this method, peptides labeled with ${ }^{13} \mathrm{C}$ and ${ }^{15} \mathrm{~N}$ are synthesized and added to the tryptic digest. By comparing peaks of the added peptide to endogenous peptide, very exquisite quantitation can be achieved in what is otherwise a very nonquantitative method.

In both the intricate processes of cell migration in EMT and the complex TGF- $\beta$ signaling pathways used in specifying the behavior of cells at that time, it is often difficult to perceive the core processes. Therefore, the problem lies in establishing an accurate model of flow of information in TGF- $\beta$ pathways. However, given the complexity of TGF- $\beta$ signaling mechanisms which are system- and cell type-specific, measurement of the rates and fluxes through the pathways is extremely challenging. As the work in the TGF- $\beta$ signaling pathway has shown, there is a great advantage if the theory suggests that some parameter is critical to developing an accurate model and then accurately measures that parameter.

A lot of molecular information of system/tissue-specific biological processes is already available in a computer-based replica, and exploring such models may assist in better understanding of these processes [Hornberg et al., 2005]. Mapping the large kinetic model of TGF- $\beta$ induced signal transduction in terms of what controls its signal transduction activity might be worth pursuing. Studies that combine quantitative experimentation and mathematical modeling will ultimately describe the functioning of the TGF- $\beta$ pathway. Theoretical studies have elucidated principles of TGF- $\beta$ signaling networks, some of which have been confirmed experimentally. These studies have contributed much to the general understanding of the functioning of signaling networks. A general issue that often emerges when analyzing a model (either an experimental or a computational one) of a large and complex biological system is the fact that reality is more complex than the model. Intrinsic simplifications and assumptions often have to be made, since the available information on the system is not always complete.

\section{Complexity of TGF- $\beta$ Signaling (fig. 3)}

TGF- $\beta$ family members regulate EMT during embryonic organ development from gastrulation to the completion of organogenesis such as arterioventricular septa, lung morphogenesis and nephrogenic mesenchyme [Runyan et al., 1992; Sun et al., 1998; Boyer et al., 1999; Cui and Shuler, 2000; Blavier et al., 2001; Wakefield et al., 2001; Kohama et al., 2002; Nawshad and Hay, 2003; Xu et al., 2003; Dudas and Kaartinen, 2005; Zavadil and Bottinger, 2005]. Specification of cells to a phenotypic pathway that includes EMT is obviously an important first step in a successful EMT. Unless the entire pathway is turned on at the right time and place, cells fail to undergo a complete EMT [Ciruna et al., 1997; Rossant et al., 1997]. This is probably not the result of the failure to regulate one or two specific molecules, but a failure to turn on the entire EMT pathway, as part of the specification event for a particular type of mesenchymal cell. Some of the receptors that may mediate developmental EMTs [e.g. TGF- $\beta$, fibroblast growth factor receptor (FGFR) and hepatocyte growth factor (HGF) receptor] are tyrosine kinase receptors, which have been shown to be involved in turning on a wide range of cell processes important for EMT [Savagner, 2001].

Binding of TGF- $\beta$ causes formation of the heteromer-

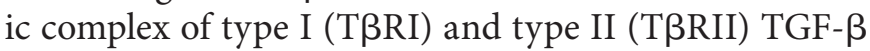
receptors [Moustakas et al., 1993]. The primary function of T $\beta R I$ is to bind to and phosphorylate the Smad proteins [Derynck et al., 1998]. To date, members of the TGF$\beta$ superfamily are the only known activators of T $\beta R I$ that elicit signaling to Smads [Dennler et al., 2002]. T $\beta R I-d e-$ pendent phosphorylation of $\operatorname{Smad} 2$ is required to permit association with Smad4, and subsequent nuclear translocation [Derynck et al., 1998; Derynck and Zhang, 2003]. The phosphorylated Smad2 (pSmad2)-Smad4 complex binds to the Smad binding element (SBE) of target genes [Tsukazaki et al., 1998; ten Dijke and Hill, 2004; Massague et al., 2005].

Although the Smads are central transducers of TGF- $\beta$, TGF- $\beta$ can also signal in a Smad-independent manner, mimicking signal transduction patterns downstream of receptor tyrosine kinases [Hu et al., 1999; Laping et al., 2002; Kamaraju and Roberts, 2004; Imamichi et al., 2005] by activating MAPK [Hu et al., 1999; Mulder, 2000; Watanabe et al., 2001; Goldberg et al., 2002; Janda et al., 2002; Wang et al., 2002; Nawshad et al., 2004; Javelaud and Mauviel, 2005], RhoA [Engel et al., 1999; Adnane et al., 2002; Clements et al., 2005; Ozdamar et al., 2005] and 
phosphatidylinositol 3-kinase (PI3K) [Bakin et al., 2000; Janda et al., 2002; Nawshad et al., 2005; Yi et al., 2005] to induce numerous transcription factors, some which are implicated in embryonic EMT such as Snail [Valdes et al., 2002; Peinado et al., 2003; Jamora et al., 2005], Slug [Duband et al., 1995; Romano and Runyan, 2000; Kang and

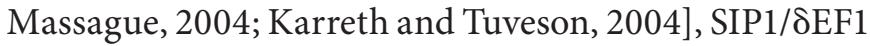
[Bolos et al., 2003; Stemmler et al., 2003; Van de Putte et al., 2003], Twist [Kang and Massague, 2004; Karreth and Tuveson, 2004], Id2/3 [Xie et al., 2003; Kowanetz et al., 2004; Valcourt et al., 2005], E12/E47 [Perez-Moreno et al., 2001], E2A [Kondo et al., 2004] and LEF1 [Nishita et al., 2000; Nawshad and Hay, 2003; Sasaki et al., 2003]. Snail and Slug seem to be involved in the disassembly of the adherens junctions by repressing E-cadherin translation [Batlle et al., 2000; Cano et al., 2000; Bolos et al., 2003], disassembly of desmosomes [Savagner et al., 1997] and tight junctions [Ikenouchi et al., 2003] by unknown mechanisms. All of these roles may be directly related to repressing E-cadherin expression as simply blocking Ecadherin binding will also cause an EMT. E-cadherin thus appears to be an important central regulator of EMT, by modulating adhesion, cytoskeletal anchoring and junctional scaffold stabilization [Liu et al., 2005]. We will come back to the detailed mechanism of repression of this key regulatory protein, E-cadherin, in EMT.

While Smads are involved in disassembly of adherens junctions [Ohnishi et al., 2004; Moustakas and Heldin, 2005] and cell cycle arrest [Pardali et al., 2005], they alone cannot activate mesenchymal markers like fibronectin [Hummer et al., 2003]. Signaling through MKK3/6p38MAPK activates the promoters of the fibronectin [Ren et al., 1999; Grille et al., 2003] and vimentin genes [Valdes et al., 2002; Wang et al., 2004] and the MEK1/2ERK1/2 pathway seems to contribute to activating transcription factors such as Snail [Cano et al., 2000; Fearon, 2003; Peinado et al., 2003] and Slug [Hajra et al., 2002]. Active ERK has several cytoplasmic and nuclear targets, such as transcription factors that influence expression of genes involved in EMT [Mulder, 2000; Chow et al., 2001; Galetic et al., 2003; Xie et al., 2004]. RhoA is another important effector of EMT because of its contribution to cytoskeletal remodeling, which facilitates cell motility [Bhowmick et al., 2001; Smith et al., 2003; Aspenstrom et al., 2004; Clements et al., 2005]. Finally, PI3K signaling has been shown to be prosurvival and antiapoptotic [Bakin et al., 2000; Janda et al., 2002; Horowitz et al., 2004; Larue and Bellacosa, 2005; Nawshad et al., 2005]. Thus, induction of EMT might require cooperation between MAPKs, RhoA, PI3K and Smad pathways, illustrating the complexity of signaling downstream of TGF- $\beta$ and the possibility of cell type-specific responses. It is, however, worth noting that the Smad-dependent pathway is absolutely critical for EMT [Lutz and Knaus, 2002; Shi and Massague, 2003; ten Dijke and Hill, 2004; Javelaud and Mauviel, 2005; Moustakas and Heldin, 2005; Valcourt et al., 2005].

As EMT progresses, the cells cease to proliferate, allowing transformation to a mesenchymal phenotype. TGF- $\beta$ has multiple roles including being a potent growth inhibitor of epithelial cells and has been associated with effects on G1 phase cyclins, cyclin-dependent kinases (CDKs), and CDK inhibitors [Yue and Mulder, 2001; Takahashi et al., 2004; Vega et al., 2004; Pardali et al., $2005]$. Using Smad and non-Smad pathways, TGF- $\beta$ signaling through ALK5/TßRI could induce a growth inhibitory response via p21/p15 [Matsuyama et al., 2003]. Recent studies [Donovan et al., 2002; Yan et al., 2002] used mouse mammary epithelial cells to show that cyclin D1, CDK4 and cyclin A were downregulated and that the cell cycle inhibitors p15, p21 and p27 were upregulated within $1 \mathrm{~h}$ of TGF- $\beta$ treatment. Thus it is likely that one role of TGF- $\beta$ is to induce growth arrest in the process of EMT [Xie et al., 2003].

Reactions that lead to the internalization of TGF- $\beta$ receptor-associated complexes exert negative control (4-5 times less than the most important reactions) on duration and integrated output. This means that, even though signaling from TGF- $\beta$ receptors continues after internalization [Hayes et al., 2002; Penheiter et al., 2002], a change in the rate of internalization still affects the output of ERK signaling [Mulder, 2000], possibly because internalized TGF- $\beta$ receptors are exclusively targeted for degradation.

The model of the TGF- $\beta$-induced MAPK signaling network is not complete yet and will require continuous updates wherever possible. The fact that we found that most reactions of this complex network are important for the output of the system suggests that the system displays a certain unexpected robustness and, hence, that many simplifications (reactions that are not in the model but do function in reality) may not affect the outcome nor our conclusions to a large extent.

In summary, it is yet to be determined which reactions in the complex TGF- $\beta$-induced MAPK network are important and which are not. Control analysis of accurate mathematical models incorporating real-time enzymological quantitative and kinetic measurements are a promising tool for the understanding and prediction of the functioning of complex TGF- $\beta$ signaling networks. 
Activation of TGF- $\beta$ Receptor

There are seven known (ALK1-7) type I receptors and five type II. Unique combinations of type I and II receptors confer specificity of ligand signaling [Piek and Roberts, 2001; Byfield and Roberts, 2004]. Studies done by Prof. Harvey Lodish [Luo et al., 1995; Luo and Lodish, 1996, 1997] demonstrated that while complex formation by the different TGF- $\beta$ family isoforms is fairly simple and uniform, it is the cytoplasmic tail of the receptors that propagates downstream signaling, particularly the selectivity of downstream pathways. They have shown that TßRII kinase is regulated intricately by autophosphorylation on at least three serine residues (Ser 203, 409 and 416) resembling autophosphorylation of tyrosine residues in kinase by MAPK, platelet-derived growth factors (PDGF), colony-stimulating factor and insulin-like growth factors (IGF).

Phosphorylation of these sites could be involved directly in the recruitment of and binding of the substrate in a manner similar to that of phosphotyrosine binding to $\mathrm{SH} 2$ or PTB domains, thus facilitating a protein-protein interaction with Raf1 [Luo and Lodish, 1997]. A recent paper by Ozdamar et al. [2005] has shown that TßRII kinase phosphorylate Ser 345 residue of T $\beta R I$ directly interacting with Par6, a new signaling molecule which mediates the localization of RhoA to enable TGF- $\beta$-dependent dissolution of tight junctions during EMT without activating Smad pathway. This is a remarkable finding and confirms a direct evidence of TGF- $\beta$ signaling via the Smad-independent pathway during EMT. ALK4,5 and 7 are strictly TGF- $\beta$ signaling receptors (not BMPs or activins) [DaCosta Byfield et al., 2004]; however, if the L45 loop residues of ALK5 are mutated, only Smad activation is diminished, not non-Smad pathways [Valcourt et al., 2005]. It is still not known which isoform of TGF- $\beta$ signals via Smad-dependent and/or Smad-independent pathways. But most [Bakin et al., 2000; Watanabe et al., 2001; Yan et al., 2002; Peinado et al., 2003] agree that TGF- $\beta$ signals via both the Smad-dependent and Smadindependent pathways. While the rule of thumb is that TGF- $\beta$ superfamily signals via Smad-dependent mechanism, there is ample evidence that these pathways crosstalk to each other [Bakin et al., 2000; Lutz and Knaus, 2002; Yan et al., 2002; Peinado et al., 2003; Moustakas and Heldin, 2005; Xia and Cheng, 2005], in a cell/tissue type-specific manner. It is, however, worth noting that, although TGF- $\beta$ can signal via the Smad-independent pathway, the Smad-dependent pathway is absolutely critical for EMT [Moustakas and Heldin, 2005; Valcourt et al., 2005].
The problem is not the fact that TGF- $\beta$ is capable of signaling via both Smad-dependent or Smad-independent pathways but how and why TGF- $\beta$ would do that. Do different arms of the TGF- $\beta$ pathways activate different EMT genes? How is this selectivity controlled by TGF- $\beta$ ? Lastly, but more importantly, since other growth factors (PDGF, IGF, epidermal growth factor, HFG as shown in fig. 4) can quite effectively signal via RTK by activating several molecules shared by TGF-Smad-independent pathways in certain cell types, it is not unusual for TGF- $\beta$ to share its role with other growth factors in EMT in development [Yamane et al., 2003; Karihaloo et al., 2005; Mukherjee et al., 2005; Gwon, 2006; Yoshiji et al., 2006].

\section{One Pathway or Multiple Pathways - That Is the Question}

As stated by Gerhart [1999] during his 1998 Warkany lecture on Signaling Pathways in Development, there are seventeen signal transduction pathways recognized in development. Five of these pathways are used repeatedly in the early development; five more are used in later development, that is in organogenesis and cytodifferentiation. The remaining seven are used almost entirely in the physiological functioning of the fetus, juvenile, and adult, which is accomplished by differentiated cells.

Therefore, it would not be unexpected for other ligands to cooperatively signal with TGF- $\beta$ to facilitate EMT. Because in reorganizing germ layers during early development EMT is the most active and probably main mechanism of germ layer segmentation, all five pathways might be involved in facilitating error-free EMT. However, given the uniqueness and multiple roles that TGF- $\beta$ plays in cell behavior, the idea of single-handedly completing all features of EMT cannot be totally ruled out either. One important test of the value of the modeling and data acquisition will be the ability to understand how a single ligand signals via multiple different pathways to produce different outputs.

\section{Should EMT Be Classified?}

EMT is evident in three major physiological and pathophysiological contexts, including embryonic development and morphogenesis, cancer progression and metastasis, and chronic degenerative, fibrotic disorders of mature organs. Interestingly, it is widely accepted that EMT is a uniform process regardless of context. However, this assumption seems overly simplistic and may require further investigation. As reviewed recently [Zavadil and Bottinger, 2005], developmental EMT affects tissues on a 
'global' scale that is highly coordinated, subtle, synchronized and often reversible (mesenchymal-epithelial transition in kidney tubules). In cancer progression, 'oncogenic' EMT refers to clusters of malignant cells that lose epithelial characteristics and acquire self-sustained migratory and highly matrix-invasive cell phenotypes. Oncogenic EMT is very aggressive, uncontrolled and typically considered as 'complete' and 'irreversible' EMT. Cancer cells, unlike developing cells, are self-sufficient with autocrine loops of mitogenic signaling and mechanisms to evade apoptosis [Gotzmann et al., 2004].

Least well understood and least accepted is the process of EMT that is described in the context of epithelial stress and/or injury in kidney, liver and lung or nonmalignant EMT [Zavadil and Bottinger, 2005]. In contrast with oncogenic EMT, nonmalignant transitioning cells are difficult to track, making it difficult to determine their exact fate and scope. In biopsies of diseased human kidney, single epithelial cells in tubular structures may show molecular evidence for EMT by coexpression of epithelial and mesenchymal markers [Vongwiwatana et al., 2005]. Although EMT has been widely adopted as an important mechanism that underlies epithelial degeneration and tissue fibrosis, the extent to which transitioning fibroblastoid cells contribute to accumulation of fibroblasts and ECM still remains unclear. Evidence for EMT in experimental models or human samples of these diseases is rare [Rastaldi et al., 2002]. In addition, the ultimate fate of nonmalignant transitioning fibroblastoid cells remains unclear and it is not known whether the mesenchymal cell state is reversible or irreversible [Zavadil and Bottinger, 2005].

Considering all aspects of EMT and its variations in different conditions, a universal definition to describe phenotypic features (modules) that are common manifestations of distinct biological processes with fundamentally different scope and outcomes, depending on the pathophysiological context (developmental EMT, oncogenic EMT, nononcogenic EMT), is questionable. Thus, the so-called 'universal' regulators and pathways controlling processes that manifest as EMT should be viewed with caution [Zavadil and Bottinger, 2005]. It is more likely to be a variety of different and modifiable molecular signaling networks and mediators capable of cooperating to induce manifestations consistent with EMT, depending on the physiological context and type of epithelia [Zavadil and Bottinger, 2005].

\section{Conclusion}

EMT is a highly conserved and fundamental process that governs morphogenesis in development, and may also contribute to cancer metastasis [Thiery, 2003b]. Evidence suggests that perturbation of TGF- $\beta$ signaling contributes to tumorigenesis, especially in cancers of epithelial origin [Yue and Mulder, 2001; Muraoka et al., 2002; Valdes et al., 2002; Lenferink et al., 2004; Imamichi et al., 2005]. Moreover, it should be pointed out that, in the aging animal, the mechanisms that activate embryonic mesenchymal transformation may induce spreading of cancers through the ECM and cause several other pathological conditions, such as excessive fibrosis [Hay, 2005]. The analysis of signal transduction pathways is a critically important area of developmental and cancer biology, where many defects occur in these pathways.

We do not question the importance of TGF- $\beta$ signaling in EMT nor do we dispute its complexity, but we think it is worth asking to what extent 'the cellular decisions' with respect to division, differentiation and apoptosis, involve TGF- $\beta$ signal transduction. The complexity of TGF- $\beta$ signal transduction networks is overwhelming because of the large numbers of interacting constituents, their complicated circuitry involving feedforward, feedback and crosstalk, and because of the fact that the kinetics of interaction matter. As a result of this complexity, apparently simple but highly important questions remain unanswered. Such questions may be answered by detailed and extensive quantitative experimentation with inhibitors and activators of signal transduction proteins. However, both the arsenal and the specificity of these are limited. The frustrating conclusion seems to be that notwithstanding the considerable and increasing amount of molecular information concerning TGF- $\beta$ signal transduction pathways, we have no way yet of understanding how they are controlled, and hence no rational ways of finding targets for interfering with the processes. The key to understanding cell migration, motility and invasiveness during EMT lies not only in the instructions the cells carry with them; the characteristics of the landscape also determine the way cells move around during development.

\section{Acknowledgment}

This work was supported by NIH-CoBRE grant (RR018759) to Dr. M.J. Wheelock. 


\section{References}

Adnane, J., E. Seijo, Z. Chen, F. Bizouarn, M. Leal, S.M. Sebti, T. Munoz-Antonia (2002) RhoB, not RhoA, represses the transcription of the transforming growth factor beta type II receptor by a mechanism involving activator protein 1. J Biol Chem 277: 8500-8507.

-Aspenstrom, P., A. Fransson, J. Saras (2004) Rho GTPases have diverse effects on the organization of the actin filament system. Biochem J 377: 327-337.

Asthagiri, A.R., D.A. Lauffenburger (2000) Bioengineering models of cell signaling. Annu Rev Biomed Eng 2: 31-53.

-Asthagiri, A.R., D.A. Lauffenburger (2001) A computational study of feedback effects on signal dynamics in a mitogen-activated protein kinase (MAPK) pathway model. Biotechnol Prog 17: 227-239.

Bakin, A.V., A.K. Tomlinson, N.A. Bhowmick, H.L. Moses, C.L. Arteaga (2000) Phosphatidylinositol 3-kinase function is required for transforming growth factor beta-mediated epithelial to mesenchymal transition and cell migration. J Biol Chem 275: $36803-$ 36810 .

Batlle, E., E. Sancho, C. Franci, D. Dominguez, M. Monfar, J. Baulida, A. Garcia de Herreros (2000) The transcription factor snail is a repressor of E-cadherin gene expression in epithelial tumour cells. Nat Cell Biol 2: 84-89.

Bhowmick, N.A., M. Ghiassi, A. Bakin, M. Aakre, C.A. Lundquist, M.E. Engel, C.L. Arteaga, H.L. Moses (2001) Transforming growth factor-betal mediates epithelial to mesenchymal transdifferentiation through a RhoA-dependent mechanism. Mol Biol Cell 12: $27-36$.

Birchmeier, W., J. Behrens, K.M. Weidner, J. Hulsken, C. Birchmeier (1996) Epithelial differentiation and the control of metastasis in carcinomas. Curr Top Microbiol Immunol 213: 117-135.

Blavier, L., A. Lazaryev, J. Groffen, N. Heisterkamp, Y.A. DeClerck, V. Kaartinen (2001) TGF-beta3-induced palatogenesis requires matrix metalloproteinases. Mol Biol Cell 12: 1457-1466.

Bolos, V., H. Peinado, M.A. Perez-Moreno, M.F. Fraga, M. Esteller, A. Cano (2003) The transcription factor Slug represses E-cadherin expression and induces epithelial to mesenchymal transitions: a comparison with Snail and E47 repressors. J Cell Sci 116: 499-511.

Boyer, A.S., I.I. Ayerinskas, E.B. Vincent, L.A. McKinney, D.L. Weeks, R.B. Runyan (1999) TGFbeta2 and TGFbeta 3 have separate and sequential activities during epithelial-mesenchymal cell transformation in the embryonic heart. Dev Biol 208: 530-545.

Byfield, S.D., A.B. Roberts (2004) Lateral signaling enhances TGF-beta response complexity. Trends Cell Biol 14: 107-111.
Cano, A., M.A. Perez-Moreno, I. Rodrigo, A. Locascio, M.J. Blanco, M.G. del Barrio, F. Por tillo, M.A. Nieto (2000) The transcription factor snail controls epithelial-mesenchymal transitions by repressing E-cadherin expression. Nat Cell Biol 2: 76-83.

Chow, S., H. Patel, D.W. Hedley (2001) Measurement of MAP kinase activation by flow cytometry using phospho-specific antibodies to MEK and ERK: potential for pharmacodynamic monitoring of signal transduction in hibitors. Cytometry 46: 72-78.

Ciruna, B.G., L. Schwartz, K. Harpal, T.P. Yamaguchi, J. Rossant (1997) Chimeric analysis of fibroblast growth factor receptor-1 (Fgfr1) function: a role for FGFR1 in morphogenetic movement through the primitive streak. Development 124: 2829-2841.

Clements, R.T., F.L. Minnear, H.A. Singer, R.S. Keller, P.A. Vincent (2005) RhoA and Rhokinase dependent and independent signals mediate TGF-beta-induced pulmonary endothelial cytoskeletal reorganization and permeability. Am J Physiol Lung Cell Mol Physiol 288: L294-L306.

Cui, X.M., C.F. Shuler (2000) The TGF-beta type III receptor is localized to the medial edge epithelium during palatal fusion. Int J Dev Biol 44: 397-402.

DaCosta Byfield, S., C. Major, N.J. Laping, A.B. Roberts (2004) SB-505124 is a selective inhibitor of transforming growth factor-beta type I receptors ALK4, ALK5, and ALK7. Mol Pharmacol 65: 744-752.

Danuser, G. (2005) Coupling the dynamics of two actin networks - new views on the mechanics of cell protrusion. Biochem Soc Trans 33: 1250-1253.

Dennler, S., M.J. Goumans, P. ten Dijke (2002) Transforming growth factor beta signal transduction. J Leukoc Biol 71: 731-740.

Derynck, R., Y. Zhang, X.H. Feng (1998) Smads: transcriptional activators of TGF-beta responses. Cell 95: 737-740.

Derynck, R., Y.E. Zhang (2003) Smad-dependent and Smad-independent pathways in TGF-beta family signalling. Nature 425 577-584.

Donovan, J.C., J.M. Rothenstein, J.M. Slingerland (2002) Non-malignant and tumor-derived cells differ in their requirement for p27Kip1 in transforming growth factorbeta-mediated G1 arrest. J Biol Chem 277: 41686-41692.

Duband, J.L., F. Monier, M. Delannet, D. Newgreen (1995) Epithelium-mesenchyme transition during neural crest development. Acta Anat (Basel) 154: 63-78.

Dudas, M., V. Kaartinen (2005) Tgf-beta superfamily and mouse craniofacial development: interplay of morphogenetic proteins and receptor signaling controls normal formation of the face. Curr Top Dev Biol 66: 65-133.
Engel, M.E., M.A. McDonnell, B.K. Law, H.L. Moses (1999) Interdependent SMAD and JNK signaling in transforming growth factor-beta-mediated transcription. J Biol Chem 274: 37413-37420

Fearon, E.R. (2003) Connecting estrogen receptor function, transcriptional repression, and E-cadherin expression in breast cancer. Cancer Cell 3: 307-310.

Fell, P.L., A.J. Hudson, M.A. Reynolds, N. Usman, S. Akhtar (1997) Cellular uptake properties of a 2'-amino/2'-O-methyl-modified chimeric hammerhead ribozyme targeted to the epidermal growth factor receptor mRNA. Antisense Nucleic Acid Drug Dev 7: 319326.

Galetic, I., S.M. Maira, M. Andjelkovic, B.A. Hemmings (2003) Negative regulation of ERK and Elk by protein kinase B modulates c-Fos transcription. J Biol Chem 278: 44164423.

Gerhart, J. (1999) 1998 Warkany lecture: signaling pathways in development. Teratology 60 : 226-239.

Goldberg, P.L., D.E. MacNaughton, R.T. Clements, F.L. Minnear, P.A. Vincent (2002) p38 MAPK activation by TGF-betal increases MLC phosphorylation and endothelial monolayer permeability. Am J Physiol Lung Cell Mol Physiol 282: L146-L154.

Gotzmann, J., M. Mikula, A. Eger, R. SchulteHermann, R. Foisner, H. Beug, W. Mikulits (2004) Molecular aspects of epithelial cell plasticity: implications for local tumor invasion and metastasis. Mutat Res 566: 9-20.

Grille, S.J., A. Bellacosa, J. Upson, A.J. KleinSzanto, F. van Roy, W. Lee-Kwon, M. Donowitz, P.N. Tsichlis, L. Larue (2003) The protein kinase Akt induces epithelial mesenchymal transition and promotes enhanced motility and invasiveness of squamous cell carcinoma lines. Cancer Res 63: 2172-2178.

Grunert, S., M. Jechlinger, H. Beug (2003) Diverse cellular and molecular mechanisms contribute to epithelial plasticity and metastasis. Nat Rev Mol Cell Biol 4: 657-665.

Gwon, A. (2006) Lens regeneration in mammals: a review. Surv Ophthalmol 51: 51-62.

Hajra, K.M., D.Y. Chen, E.R. Fearon (2002) The SLUG zinc-finger protein represses E-cadherin in breast cancer. Cancer Res 62: 16131618.

Hay, E.D. (2005) The mesenchymal cell, its role in the embryo, and the remarkable signaling mechanisms that create it. Dev Dyn 233: 706-720.

Hayes, S., A. Chawla, S. Corvera S (2002) TGF beta receptor internalization into EEA1-enriched early endosomes: role in signaling to Smad2. J Cell Biol 158: 1239-1249.

Heinrich, R., B.G. Neel, T.A. Rapoport (2002) Mathematical models of protein kinase signal transduction. Mol Cell 9: 957-970. 
Herman, I.M., N.J. Crisona, T.D. Pollard (1981) Relation between cell activity and the distribution of cytoplasmic actin and myosin. J Cell Biol 90: 84-91.

-Hornberg, J.J., B. Binder, F.J. Bruggeman, B. Schoeberl, R. Heinrich, H.V. Westerhoff (2005) Control of MAPK signalling: from complexity to what really matters. Oncogene 24: 5533-5542.

Horowitz, J.C., D.Y. Lee, M. Waghray, V.G. Keshamouni, P.E. Thomas, H. Zhang, Z. Cui, V.J. Thannickal (2004) Activation of the prosurvival phosphatidylinositol 3-kinase/AKT pathway by transforming growth factorbetal in mesenchymal cells is mediated by p38 MAPK-dependent induction of an autocrine growth factor. J Biol Chem 279: 13591367.

Hu, P.P., X. Shen, D. Huang, Y. Liu, C. Counter, X.F. Wang (1999) The MEK pathway is required for stimulation of p21(WAF1/CIP1) by transforming growth factor-beta. J Biol Chem 274: 35381-35387.

-Hummer, B.T., C. Bartlett, E. Henry, B.E. Weissman (2003) Expression of Smad4 in the FaDu cell line partially restores TGF-beta growth inhibition but is not sufficient to regulate fibronectin expression or suppress tumorigenicity. J Cell Physiol 194: 289-302.

Ikenouchi, J., M. Matsuda, M. Furuse, S. Tsukita (2003) Regulation of tight junctions during the epithelium-mesenchyme transition: direct repression of the gene expression of claudins/occludin by Snail. J Cell Sci 116: 19591967.

Imamichi, Y., O. Waidmann, R. Hein, P. Eleftheriou, K. Giehl, A. Menke (2005) TGF betainduced focal complex formation in epithelial cells is mediated by activated ERK and JNK MAP kinases and is independent of Smad4. Biol Chem 386: 225-236.

Jamora, C., P. Lee, P. Kocieniewski, M. Azhar, R. Hosokawa, Y. Chai, E. Fuchs (2005) A signaling pathway involving TGF-beta2 and snail in hair follicle morphogenesis. PLoS Biol 3: e11.

-Janda, E., K. Lehmann, I. Killisch, M. Jechlinger, M. Herzig, J. Downward, H. Beug, S. Grunert (2002) Ras and TGF[beta] cooperatively regulate epithelial cell plasticity and metastasis: dissection of Ras signaling pathways. J Cell Biol 156: 299-313.

Javelaud, D., A. Mauviel (2005) Crosstalk mechanisms between the mitogen-activated protein kinase pathways and Smad signaling downstream of TGF-beta: implications for carcinogenesis. Oncogene 24: 5742-5750.

-Kamaraju, A.K., A.B. Roberts (2004) Role of Rho/ROCK and p38 MAP kinase pathways in TGF-beta-mediated Smad-dependent growth inhibition of human breast carcinoma cells in vivo. J Biol Chem 2005;280:10241036.
Kang, Y., J. Massague (2004) Epithelial-mesenchymal transitions: twist in development and metastasis. Cell 118: 277-279.

Karihaloo, A., C. Nickel, L.G. Cantley (2005) Signals which build a tubule. Nephron Exp Nephrol 100: e40-45.

Karreth, F., D.A. Tuveson (2004) Twist induces an epithelial-mesenchymal transition to facilitate tumor metastasis. Cancer Biol Ther 3: 1058-1059.

Kohama, K., K. Nonaka, R. Hosokawa, L. Shum, M. Ohishi (2002) TGF-beta-3 promotes scarless repair of cleft lip in mouse fetuses. J Dent Res 81: 688-694.

Kondo, M., E. Cubillo, K. Tobiume, T. Shirakihara, N. Fukuda, H. Suzuki, K. Shimizu, K. Takehara, A. Cano, M. Saitoh, K. Miyazono (2004) A role for Id in the regulation of TGFbeta-induced epithelial-mesenchymal transdifferentiation. Cell Death Differ 11: $1092-$ 1101.

-Kowanetz, M., U. Valcourt, R. Bergstrom, C.H. Heldin, A. Moustakas (2004) Id 2 and Id 3 define the potency of cell proliferation and differentiation responses to transforming growth factor beta and bone morphogenetic protein. Mol Cell Biol 24: 4241-4254.

Laping, N.J., E. Grygielko, A. Mathur, S. Butter, J. Bomberger, C. Tweed, W. Martin, J. Fornwald, R. Lehr, J. Harling, L. Gaster, J.F. Callahan, B.A. Olson (2002) Inhibition of transforming growth factor (TGF)-beta1-induced extracellular matrix with a novel inhibitor of the TGF-beta type I receptor kinase activity: SB-431542. Mol Pharmacol 62: 58-64.

Larue, L., A. Bellacosa (2005) Epithelial-mesenchymal transition in development and cancer: role of phosphatidylinositol 3' kinase/ AKT pathways. Oncogene 24: 7443-7454.

Lenferink, A.E., J. Magoon, C. Cantin, M.D. O'Connor-McCourt (2004) Investigation of three new mouse mammary tumor cell lines as models for transforming growth factor (TGF)-beta and Neu pathway signaling studies: identification of a novel model for TGFbeta-induced epithelial-to-mesenchymal transition. Breast Cancer Res 6: R514-530.

Levchenko, A., J. Bruck, P.W. Sternberg (2000) Scaffold proteins may biphasically affect the levels of mitogen-activated protein kinase signaling and reduce its threshold properties. Proc Natl Acad Sci USA 97: 5818-5823.

Liu, Y.N., W.W. Lee, C.Y. Wang, T.H. Chao, Y. Chen, J.H. Chen (2005) Regulatory mechanisms controlling human E-cadherin gene expression. Oncogene 2005;24:8277-8290.

Luo, K, H.F. Lodish (1996) Signaling by chimeric erythropoietin-TGF-beta receptors: homodimerization of the cytoplasmic domain of the type I TGF-beta receptor and heterodimerization with the type II receptor are both required for intracellular signal transduction. EMBO J 15: 4485-4496.
Luo, K., H.F. Lodish (1997) Positive and negative regulation of type II TGF-beta receptor signal transduction by autophosphorylation on multiple serine residues. EMBO J 16: $1970-$ 1981.

Luo, K., P. Zhou, H.F. Lodish (1995) The specificity of the transforming growth factor beta receptor kinases determined by a spatially addressable peptide library. Proc Natl Acad Sci USA 92: 11761-11765.

Lutz, M., P. Knaus (2002) Integration of the TGF-beta pathway into the cellular signalling network. Cell Signal 14: 977.

Massague, J., J. Seoane, D. Wotton (2005) Smad transcription factors. Genes Dev 19: $2783-$ 2810.

Matsuyama, S., M. Iwadate, M. Kondo, M. Saitoh, A. Hanyu, K. Shimizu, H. Aburatani, H.K. Mishima, T. Imamura, K. Miyazono, K. Miyazawa (2003) SB-431542 and Gleevec inhibit transforming growth factor-beta-induced proliferation of human osteosarcoma cells. Cancer Res 63: 7791-7798.

Moustakas, A., C.H. Heldin (2005) Non-Smad TGF-beta signals. J Cell Sci 118: 3573-3584.

Moustakas, A., H.Y. Lin, Y.I. Henis, J. Plamondon, M.D. O'Connor-McCourt, H.F. Lodish (1993) The transforming growth factor beta receptors types I, II, and III form heterooligomeric complexes in the presence of ligand. J Biol Chem 268: 22215-22218.

Mukherjee, A., S.S. Dong, T. Clemens, J. Alvarez, R. Serra (2005) Co-ordination of TGF-beta and FGF signaling pathways in bone organ cultures. Mech Dev 122: 557-571.

Mulder, K.M. (2000) Role of Ras and Mapks in TGFbeta signaling. Cytokine Growth Factor Rev 11: 23-35.

Muraoka, R.S., N. Dumont, C.A. Ritter, T.C. Dugger, D.M. Brantley, J. Chen, E. Easterly, L.R. Roebuck, S. Ryan, P.J. Gotwals, V. Koteliansky, C.L. Arteaga (2002) Blockade of TGF-beta inhibits mammary tumor cell viability, migration, and metastases. J Clin Invest 109: 1551-1559.

- Nawshad, A., E.D. Hay (2003) TGFbeta3 signaling activates transcription of the LEF1 gene to induce epithelial mesenchymal transformation during mouse palate development. J Cell Biol 163: 1291-1301.

-Nawshad, A., D. LaGamba, E.D. Hay (2004) Transforming growth factor beta (TGFbeta) signalling in palatal growth, apoptosis and epithelial mesenchymal transformation (EMT). Arch Oral Biol 49: 675-689.

Nawshad, A., D. LaGamba, A. Polad, E.D. Hay (2005) Transforming growth factor-beta signaling during epithelial-mesenchymal transformation: implications for embryogenesis and tumor metastasis. Cells Tissues Organs 179: 11-23.

Nishita, M., M.K. Hashimoto, S. Ogata, M.N. Laurent, N. Ueno, H. Shibuya, K.W. Cho (2000) Interaction between Wnt and TGFbeta signalling pathways during formation of Spemann's organizer. Nature 403: 781785. 
Ohnishi, H., T. Miyata, H. Yasuda, Y. Satoh, K. Hanatsuka, H. Kita, A. Ohashi, K. Tamada, N. Makita, T. Iiri, N. Ueda, H. Mashima, K. Sugano (2004) Distinct roles of Smad2-, Smad3-, and ERK-dependent pathways in transforming growth factor-betal regulation of pancreatic stellate cellular functions. J Biol Chem 279: 8873-8878.

-Ozdamar, B., R. Bose, M. Barrios-Rodiles, H.R. Wang, Y. Zhang, J.L. Wrana (2005) Regulation of the polarity protein Par6 by TGFbeta receptors controls epithelial cell plasticity. Science 307: 1603-1609.

Pardali, K., M. Kowanetz, C.H. Heldin, A. Moustakas (2005) Smad pathway-specific transcriptional regulation of the cell cycle inhibitor p21(WAF1/Cip1). J Cell Physiol 204: 260-272.

-Peinado, H., M. Quintanilla, A. Cano (2003) Transforming growth factor beta-1 induces snail transcription factor in epithelial cell lines: mechanisms for epithelial mesenchymal transitions. J Biol Chem 278: 2111321123.

Penheiter, S.G., H. Mitchell, N. Garamszegi, M. Edens, J.J. Dore, Jr., E.B. Leof (2002) Internalization-dependent and -independent requirements for transforming growth factor beta receptor signaling via the Smad pathway. Mol Cell Biol 22: 4750-4759.

Perez-Moreno, M.A., A. Locascio, I. Rodrigo, G. Dhondt, F. Portillo, M.A. Nieto, A. Cano (2001) A new role for E12/E47 in the repression of E-cadherin expression and epithelialmesenchymal transitions. J Biol Chem 276: 27424-27431.

Piek, E., A.B. Roberts (2001) Suppressor and oncogenic roles of transforming growth factorbeta and its signaling pathways in tumorigenesis. Adv Cancer Res 83: 1-54.

Rashbass, P., H. Skaer (2000) Cell polarity: nailing Crumbs to the scaffold. Curr Biol 10: R234-236.

Rastaldi, M.P., F. Ferrario, L. Giardino, G. Dell'Antonio, C. Grillo, P. Grillo, F. Strutz, G.A. Muller, G. Colasanti, G. D’Amico (2002) Epithelial-mesenchymal transition of tubular epithelial cells in human renal biopsies. Kidney Int 62: 137-146.

Ren, X.D., W.B. Kiosses, M.A. Schwartz (1999) Regulation of the small GTP-binding protein Rho by cell adhesion and the cytoskeleton. EMBO J 18: 578-585.

Roberts, A.B. (2002) The ever-increasing complexity of TGF-beta signaling. Cytokine Growth Factor Rev 13: 3-5.

Romano, L.A., R.B. Runyan (2000) Slug is an essential target of TGFbeta2 signaling in the developing chicken heart. Dev Biol 223: 91102.

Rossant, J., B. Ciruna, J. Partanen (1997) FGF signaling in mouse gastrulation and anteroposterior patterning. Cold Spring Harb Symp Quant Biol 62: 127-133.
Runyan, R.B., J.D. Potts, D.L. Weeks (1992) TGF-beta 3-mediated tissue interaction during embryonic heart development. Mol Reprod Dev 32: 152-159.

Sasaki, T., H. Suzuki, K. Yagi, M. Furuhashi, R. Yao, S. Susa, T. Noda, Y. Arai, K. Miyazono, M. Kato (2003) Lymphoid enhancer factor 1 makes cells resistant to transforming growth factor beta-induced repression of c-myc. Cancer Res 63: 801-806.

Savagner, P. (2001) Leaving the neighborhood: molecular mechanisms involved during epithelial-mesenchymal transition. Bioessays 23: 912-923.

Savagner, P., K.M. Yamada, J.P. Thiery (1997) The zinc-finger protein slug causes desmosome dissociation, an initial and necessary step for growth factor-induced epithelialmesenchymal transition. J Cell Biol 137: 1403-1419.

Shi, Y., J. Massague (2003) Mechanisms of TGFbeta signaling from cell membrane to the nucleus. Cell 113: 685-700.

Shook, D., R. Keller (2003) Mechanisms, mechanics and function of epithelial-mesenchymal transitions in early development. Mech Dev 120: 1351-1383.

Smith, P.G., C. Roy, Y.N. Zhang, S. Chauduri (2003) Mechanical stress increases RhoA activation in airway smooth muscle cells. Am J Respir Cell Mol Biol 28: 436-442.

Stemmann, O., H. Zou, S.A. Gerber, S.P. Gygi, M.W. Kirschner (2001) Dual inhibition of sister chromatid separation at metaphase. Cell 107: 715-726.

-Stemmler, M.P., A. Hecht, B. Kinzel, R. Kemler (2003) Analysis of regulatory elements of Ecadherin with reporter gene constructs in transgenic mouse embryos. Dev Dyn 227: 238-245.

Sun, D., C.R. Vanderburg, G.S. Odierna, E.D. Hay (1998) TGFbeta3 promotes transformation of chicken palate medial edge epithelium to mesenchyme in vitro. Development 125: 95-105.

Takahashi, E., N. Funato, N. Higashihori, Y. Hata, T. Gridley, M. Nakamura (2004) Snail regulates p21(WAF/CIP1) expression in cooperation with E2A and Twist. Biochem Biophys Res Commun 325: 1136-1144.

Takeichi, M. (1991) Cadherin cell adhesion receptors as a morphogenetic regulator. Science 251: 1451-1455.

Takeichi, M. (1993) Cadherins in cancer: implications for invasion and metastasis. Curr Opin Cell Biol 5:806-811.

ten Dijke, P., C.S. Hill (2004) New insights into TGF-beta-Smad signalling. Trends Biochem Sci 29: 265-273.

Thiery, J.P. (2003a) Cell adhesion in development: a complex signaling network. Curr Opin Genet Dev 13: 365-371.

Thiery, J.P. (2003b) Epithelial-mesenchymal transitions in development and pathologies. Curr Opin Cell Biol 15: 740-746.
Thiery, J.P., J.P. Sleeman (2006) Complex networks orchestrate epithelial-mesenchymal transitions. Nat Rev Mol Cell Biol 7: 131142 .

Tsukazaki, T., T.A. Chiang, A.F. Davison, L. Attisano, J.L. Wrana (1998) SARA, a FYVE domain protein that recruits Smad2 to the TGFbeta receptor. Cell 95: 779-791.

Valcourt, U., M. Kowanetz, H. Niimi, C.H. Heldin, A. Moustakas (2005) TGF-beta and the Smad signaling pathway support transcriptomic reprogramming during epithelialmesenchymal cell transition. Mol Biol Cell 16: 1987-2002.

Valdes, F., A.M. Alvarez, A. Locascio, S. Vega, B. Herrera, M. Fernandez, M. Benito, M.A. Nieto, I. Fabregat (2002) The epithelial mesenchymal transition confers resistance to the apoptotic effects of transforming growth factor beta in fetal rat hepatocytes. Mol Cancer Res 1: 68-78.

Van de Putte, T., M. Maruhashi, A. Francis, L. Nelles, H. Kondoh, D. Huylebroeck, Y. Higashi (2003) Mice lacking ZFHX1B, the gene that codes for Smad-interacting protein-1, reveal a role for multiple neural crest cell defects in the etiology of Hirschsprung disease-mental retardation syndrome. Am J Hum Genet 72: 465-470.

Vega, S., A.V. Morales, O.H. Ocana, F. Valdes, I. Fabregat, M.A. Nieto (2004) Snail blocks the cell cycle and confers resistance to cell death. Genes Dev 18: 1131-1143.

Vongwiwatana, A., A. Tasanarong, D.C. Rayner, A. Melk, P.F. Halloran (2005) Epithelial to mesenchymal transition during late deterioration of human kidney transplants: the role of tubular cells in fibrogenesis. Am J Transplant 5: 1367-1374.

Wakefield, L.M., E. Piek, E.P. Bottinger (2001) TGF-beta signaling in mammary gland development and tumorigenesis. J Mammary Gland Biol Neoplasia 6: 67-82.

Wang, D., Q. Shen, Y.Q. Chen, M.H. Wang (2004) Collaborative activities of macrophagestimulating protein and transforming growth factor-betal in induction of epithelial to mesenchymal transition: roles of the RON receptor tyrosine kinase. Oncogene 23: 1668-1680.

Wang, L., R. Ma, R.A. Flavell, M.E. Choi (2002) Requirement of mitogen-activated protein kinase kinase 3 (MKK3) for activation of p38alpha and p38delta MAPK isoforms by TGF-beta 1 in murine mesangial cells. J Biol Chem 277: 47257-47262.

-Watanabe, H., M.P. de Caestecker, Y. Yamada (2001) Transcriptional cross-talk between Smad, ERK1/2, and p38 mitogen-activated protein kinase pathways regulates transforming growth factor-beta-induced aggrecan gene expression in chondrogenic ATDC5 cells. J Biol Chem 276: 14466-14473. 
Xia, W., C.Y. Cheng (2005) TGF-beta3 regulates anchoring junction dynamics in the seminiferous epithelium of the rat testis via the Ras/ERK signaling pathway: an in vivo study. Dev Biol 280: 321-343.

Xie, L., B.K. Law, M.E. Aakre, M. Edgerton, Y. Shyr, N.A. Bhowmick, H.L. Moses (2003) Transforming growth factor beta-regulated gene expression in a mouse mammary gland epithelial cell line. Breast Cancer Res 5 R187-198.

Xie, L., B.K. Law, A.M. Chytil, K.A. Brown, M.E. Aakre, H.L. Moses (2004) Activation of the Erk pathway is required for TGF-betal-induced EMT in vitro. Neoplasia 6: 603-610.
Xu, Z., M.X. Shen, D.Z. Ma, L.Y. Wang, X.L. Zha (2003) TGF-betal-promoted epithelial-tomesenchymal transformation and cell adhesion contribute to TGF-beta1-enhanced cell migration in SMMC-7721 cells. Cell Res 13: 343-350.

Yamane, A., O. Amano, H.C. Slavkin (2003) Insulin-like growth factors, hepatocyte growth factor and transforming growth factor-alpha in mouse tongue myogenesis. Dev Growth Differ 45: 1-6.

Yan, Z., G.Y. Kim, X. Deng, E. Friedman (2002) Transforming growth factor beta 1 induces proliferation in colon carcinoma cells by Ras-dependent, smad-independent downregulation of p21cip1. J Biol Chem 277: $9870-$ 9879.

Yi, J.Y., I. Shin, C.L. Arteaga (2005) Type I transforming growth factor beta receptor binds to and activates phosphatidylinositol 3-kinase. J Biol Chem 280: 10870-10876.
Yoshiji, H., S. Kuriyama, R. Noguchi, Y. Ikenaka, J. Yoshii, K. Yanase, T. Namisaki, M. Kitade, M. Yamazaki, K. Asada, T. Akahane, T. Tsujimoto, M. Uemura, H. Fukui (2006) Amelioration of liver fibrogenesis by dual inhibition of PDGF and TGF-beta with a combination of imatinib mesylate and ACE inhibitor in rats. Int J Mol Med 17: 899-904.

Yue, J., K.M. Mulder (2001) Transforming growth factor-beta signal transduction in epithelial cells. Pharmacol Ther 91: 1-34.

Zavadil, J., E.P. Bottinger (2005) TGF-beta and epithelial-to-mesenchymal transitions. Oncogene 24: 5764-5774. 